\title{
In Vitro Propagation of Eucomis autumnalis, E. comosa, and E. zambesiaca by Twin-scaling
}

\author{
James R. Ault ${ }^{1}$ \\ Department of Horticulture, Longwood Gardens, P.O. Box 501, Kennett \\ Square, PA 19348
}

Additional index words. micropropagation, pineapple lily, tissue culture

\begin{abstract}
Shoot formed in vitro from twin-scale explants of Eucomis autumnalis (Mill.) Chitt., E. comosa (Houtt.) Wehrh., and E. zambesiaca Bak. cultured on Murashige and Skoog (MS) basal medium containing 0.0, 4.4, 11.1, or $22.2 \mu_{\mathrm{M}}$ BA and 0.0 or 5.4 $\mu_{\mathrm{M}}$ NAA. In all three species, shoot proliferation was obtained from single-shoot explants subcultured on medium supplemented with 4.4,11.1, or $22.2 \mu \mathrm{M}$ BA and 0.0 or $5.4 \mu \mathrm{M}$ NAA. Shoots of all three species rooted readily on MS medium supplemented with $0.0,2.7,5.4$, or 10.8 $\mu_{M}$ NAA. Overall rooting percentages were $95 \%, 98 \%$, and $100 \%$ for $E$. autumnalis, $E$. comosa, and $E$. zambesiaca, respectively. Plant survival for rooted shoots of all three species was $100 \%$ following transfer to a 1 perlite : 1 peat $(\mathrm{v} / \mathrm{v})$ medium in the greenhouse. Chemical names used: 6-benzyladenine (BA); 1-naphthaleneacetic acid (NAA).
\end{abstract}

Eucomis autumnalis, E. comosa, and E. zambesiaca are summer-blooming, deciduous geophytes of the Hyacinthaceae. Eucomis can be propagated from offsets or seed; however, blooming-sized plants take three or more years from seed (Du Plessis and Duncan, 1989), and plants can be slow to form offsets. Various forms of Eucomis have been reported (Compton, 1990; de Lange et al., 1989). Tissue culture could offer a potential means of clonally propagating superior plants. De Lange et al. (1989) investigated the micropropagation of E. autumnalis and E. bicolor Bak. for conservation, restoration, and ethnobotanical uses but did not detail their protocol. To facilitate the propagation of Eucomis for horticultural or conservation needs, I report on a protocol for the twin-scale micropropagation and greenhouse establishment of E. autumnalis, E. comosa, and E. zambesiaca. The technique of twin-scaling has been effective for the tissue culture propagation of other geophyte species, including Hyacinthus (Hussey, 1975), Narcissus (Hanks and Rees, 1977), and Nerine (Pierik and Ippel, 1977).

\section{Materials and Methods}

Seed was obtained from several sources in South Africa in 1986 and germinated in 1987. The plants were grown in a greenhouse for 4 years. During that period, plants were grown individually in clay pots of varying sizes containing a medium of 4 peat : 4 vermiculite : 2 clay loam field soil : 1 hardwood charcoal (by volume). Dormant bulbs initiated seasonal

Received for publication 22 Dec. 1994. Accepted for publication 14 Aug. 1995. The cost of publishing this paper was defrayed in part by the payment of page charges. Under postal regulations, this paper therefore must be hereby marked advertisement solely to indicate this fact.

${ }^{1}$ Current address: Chicago Botanic Garden, P.O. Box 400, Glencoe, IL 60022 growth in March or April of each year and were maintained in full sun in the greenhouse until foliage died down in November or December. Dormant bulbs were stored dry in their pots under a bench in a greenhouse held at $\geq 7 \mathrm{C}$. For tissue culture, dormant bulbs were removed from their pots, and all dried foliage, roots, and dried and diseased-appearing scales were removed. Two E. autumnalis bulbs 11 $\mathrm{cm}$ in diameter, two E. comosa bulbs 4 to $6 \mathrm{~cm}$ in diameter, and four E. zambesiaca bulbs 3 to $4 \mathrm{~cm}$ in diameter were used. Bulbs were rinsed in 35 to $40 \mathrm{C}$ tap water for $30 \mathrm{~min}$ to remove soil. Each bulb was cut in half transversely, then the basal portion was cut longitudinally into four to eight wedges. The basal segments were placed in $1.0 \%$ sodium hypochlorite and $0.1 \%$ Tween 20 for $20 \mathrm{~min}$, then rinsed twice in sterile distilled water for $5 \mathrm{~min}$ each time. The bulb segments were recut transversely to within $1.0 \pm 0.5 \mathrm{~cm}$ of the basal plate. Twinscale explants, consisting of two $\approx 1.0-\mathrm{cm}^{2}$ adjoining bulb scale bases and a portion of the basal plate, were dissected from the outermost bulb scales. Explants were oriented upright and placed singly in $25 \times 150$-mm culture tubes containing $10 \mathrm{ml}$ of medium.

Media consisted of Murashige and Skoog (MS) (1962) basal salts and vitamins; $30 \mathrm{~g}$ sucrose/liter; 0.0 or $5.4 \mu \mathrm{M}$ NAA; and $0.0,4.4$, 11.1 , or $22.2 \mu \mathrm{M}$ BA. The number of shoots per explant was recorded after 8 weeks in culture. Individual microshoots then were excised and cultured onto the same fresh media. The number of shoots per microshoot explant was recorded after 8 to 10 weeks. Nonrooted shoots from explants on all media then were cultured onto MS medium containing 0.0, 2.7, 5.4, or $10.8 \mu \mathrm{m}$ NAA. Percent rooting was recorded after 8 weeks. For all studies, medium $\mathrm{pH}$ was adjusted to 5.7 with $1 \mathrm{~N} \mathrm{NaOH}$ or $1 \mathrm{~N} \mathrm{HCl}, 7.0$ g agar/liter (A 1296; Sigma Chemical Co., St. Louis) were added, then the medium was autoclaved at $121 \mathrm{C}$ for $15 \mathrm{~min}$. Culture tubes were sealed with polypropylene caps and parafilm and then placed in an incubator (model 818; Precision Scientific, Chicago) maintained at $25 \mathrm{C}$, with a 16 -h photoperiod, and with a photosynthetic photon flux (PPF) of 30 to 44 $\mu \mathrm{mol} \cdot \mathrm{m}^{-2} \cdot \mathrm{s}^{-1}$ provided by two $40-\mathrm{W}$, broadspectrum fluorescent lamps (Verilux, Greenwich, Conn.). PPF was measured with a quantum sensor (model LI-190SA; LI-COR, Lincoln, Neb.).

For greenhouse establishment, rooted shoots were rinsed free of tissue culture medium, then potted, five to seven plants each, in plastic azalea pots $(16.5 \mathrm{~cm}$ in diameter $)$ containing $\approx 3000 \mathrm{~cm}^{3}$ of 1 perlite : 1 peatmoss $(\mathrm{v} / \mathrm{v})$. Clear polyethylene bags were inverted over the pots and secured with rubber bands, and the pots were placed under $50 \%$ shadecloth on a bench in a greenhouse. The bags were ventilated by removing the rubber bands after 2 weeks; bags were removed 1 week later. For the acclimatization period, the greenhouse averaged $22 \pm 9 \mathrm{C}$ with a photoperiod of $\approx 14.5 \mathrm{~h}$.

For the shoot initiation study, 80 twinscale explants for each species were randomly assigned, 10 each to the eight treatments. For each species, 10 or 20 single shoots were selected at random and assigned to each of the eight treatments of the proliferation study and to each of the four treatments of the rooting study. The shoot initiation, proliferation, and rooting experiments each were conducted once.

Table 1. Effects of BA and NAA on shoot proliferation of Eucomis autumnalis, E. comosa, and E. zambesiaca microshoots after 8 to 10 weeks of culture on MS medium.

\begin{tabular}{|c|c|c|c|c|c|c|c|}
\hline \multicolumn{2}{|c|}{ Growth regulator $(\mu \mathrm{M})$} & \multicolumn{6}{|c|}{ No. shoots/microshoot explant } \\
\hline \multirow{2}{*}{$\begin{array}{l}\mathrm{BA} \\
0.0\end{array}$} & \multirow{2}{*}{$\frac{\text { NAA }}{0.0}$} & \multicolumn{2}{|c|}{ E. autumnalis } & \multicolumn{2}{|c|}{ E. comosa } & \multicolumn{2}{|c|}{ E. zambesiaca } \\
\hline & & \multicolumn{2}{|c|}{1.0} & \multicolumn{2}{|c|}{1.0} & \multicolumn{2}{|c|}{10} \\
\hline & 5.4 & \multicolumn{2}{|c|}{1.0} & \multicolumn{2}{|c|}{1.6} & \multicolumn{2}{|c|}{1.5} \\
\hline \multirow[t]{2}{*}{4.4} & 0.0 & \multicolumn{2}{|c|}{$--^{2}$} & \multicolumn{2}{|c|}{13} & \multicolumn{2}{|c|}{1.6} \\
\hline & 5.4 & \multicolumn{2}{|c|}{2.3} & \multicolumn{2}{|c|}{2.9} & \multicolumn{2}{|c|}{3.7} \\
\hline \multirow[t]{2}{*}{11.1} & 0.0 & \multicolumn{2}{|c|}{3.1} & \multicolumn{2}{|c|}{1.9} & \multicolumn{2}{|c|}{2.1} \\
\hline & 5.4 & \multicolumn{2}{|c|}{3.7} & \multicolumn{2}{|c|}{1.5} & \multicolumn{2}{|c|}{6.6} \\
\hline \multirow[t]{2}{*}{22.2} & 0.0 & \multicolumn{2}{|c|}{2.9} & \multicolumn{2}{|c|}{1.2} & \multicolumn{2}{|c|}{2.2} \\
\hline & 5.4 & \multicolumn{2}{|c|}{3.6} & \multicolumn{2}{|c|}{1.8} & \multicolumn{2}{|c|}{6.9} \\
\hline \multicolumn{2}{|c|}{ Source } & $\mathrm{df}$ & MS & df & MS & $\mathrm{df}$ & MS \\
\hline \multicolumn{2}{|c|}{ BA } & $\overline{3}$ & $20.63^{* *}$ & $\overline{3}$ & $\overline{6.70^{* *}}$ & $\overline{3}$ & $\overline{40.53^{\mathrm{Ns}}}$ \\
\hline \multicolumn{2}{|c|}{ NAA } & 1 & $4.10^{\mathrm{Ns}}$ & 1 & $14.20^{* *}$ & 1 & $156.30^{*}$ \\
\hline \multicolumn{2}{|c|}{$\mathrm{BA} \times \mathrm{NAA}$} & 3 & $9.07^{* *}$ & 3 & $2.07^{\mathrm{Ns}}$ & 3 & $17.43^{\text {vs }}$ \\
\hline Erro & & 58 & 1.76 & 88 & 1.39 & 71 & 37.94 \\
\hline
\end{tabular}

${ }^{2}$ Data not recorded due to loss of all plant cultures to contamination.

Ns, *,** Nonsignificant or significant at $P \leq 0.05$ or 0.01 , respectively. 


\section{Propagation \& Tissue Culture}

Shoot initiation and proliferation data were subjected to analysis of variance (ANOVA), with the source of variation including the main effects of BA and NAA and the BA $\times$ NAA interaction. Proportional data (percent rooting) were analyzed using $\chi^{2}$. Data were analyzed with CoStat statistical software (CoHort Software, Berkeley, Calif.).

\section{Results and Discussion}

Shoots arose from the region of the basal plate tissue and from cut surfaces of the bulb scales within 4 weeks of culture initiation. The effect of BA on shoot proliferation after 8 weeks of culture was highly significant $(\mathrm{F}=$ $4.53, P<0.01$, with 3 and $63 \mathrm{df}$ ) for $E$. zambesiaca. There were no other significant growth regulator effects on E. comosa or $E$. zambesiaca shoot initiation. The mean number of shoots per explant was 2.8 for both species. Data for E. autumnalis were not statistically analyzed because of high explant contamination (90\%). The mean number of shoots per surviving explant for E. autumnalis was 13.9. No one medium appeared optimal for shoot initiation for all three species.

Growth regulator effects on shoot proliferation from single-shoot explants differed for each species, with $\mathrm{BA}$ and the $\mathrm{BA} \times \mathrm{NAA}$ interaction significant for E. autumnalis, BA and NAA significant for $E$. comosa, and NAA significant for E. zambesiaca (Table 1). The combinations of $4.4,11.1$, or $22.2 \mu \mathrm{M}$ BA and 0.0 or $5.4 \mu \mathrm{M}$ NAA stimulated shoot proliferation in all three species (Fig. $1 \mathrm{~A}$ and B). There was no one medium that proved optimal for shoot proliferation for all three species. Hussey (1977) and $\mathrm{Nel}$ (1983) reported the efficacy of BA and NAA for shoot proliferation in monocotyledonous geophytes.

Growth regulators had no significant effect on percent rooting for any of the species. Overall percent rooting was $95 \%, 98 \%$, and $100 \%$ for E. autumnalis, E. comosa, and E. zambesiaca, respectively (Fig. $1 \mathrm{C}$ and D). Rooted shoots of E. autumnalis (35), E. comosa (96), and E. zambesiaca (35) were transferred to the greenhouse, and all of these plants survived acclimatization. By the end of the growing season ( $\approx 6$ months), bulbs 2 to $3 \mathrm{~cm}$ in diameter had been produced.

By using the appropriate combination of BA and NAA, several hundred plants likely can be produced from a single mother bulb within 6 months of culture initiation. Additional research is warranted to improve primary explant survival and to optimize the growth regulator concentrations for shoot initiation and proliferation for each species.

\section{Literature Cited}

Compton, J. 1990. Eucomis L'Heritier. Plantsman 12(3):129-139.

de Lange, H., S. Tennant, P. Botha, C. Klein, and G. Nichols. 1989. Micropropagation and the trade in indigenous medicinal plants. Veld \& Flora 75(2):60-61.

Du Plessis, N. and G. Duncan. 1989. Bulbous plants of southern Africa. Tafelberg Publishers, Cape Town, South Africa.
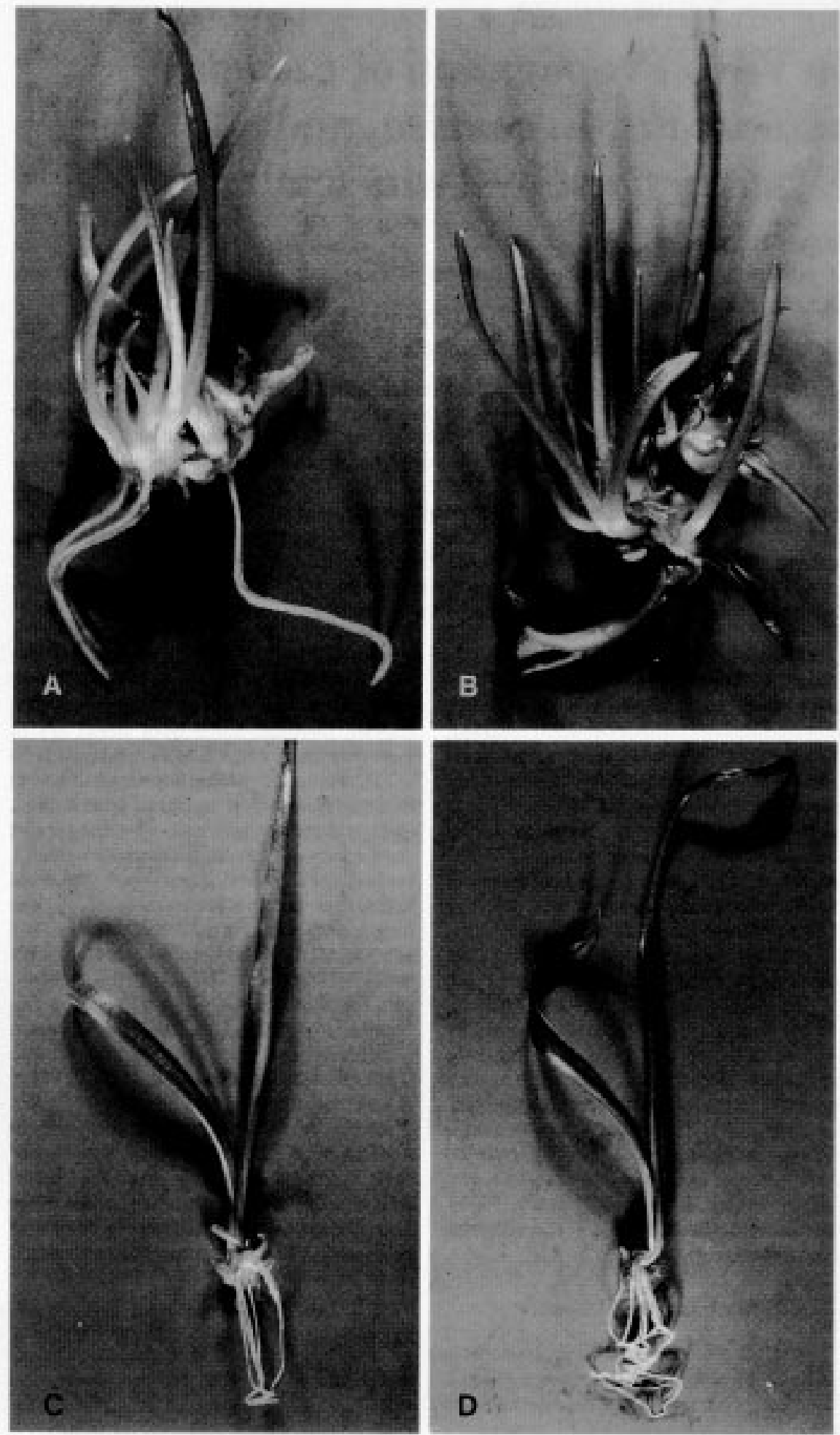

Fig. 1. Axillary shoot proliferation after 12 weeks culture for (A) Eucomis comosa on medium supplemented with $2.0 \mathrm{mg} \mathrm{BA} /$ liter and $1.0 \mathrm{mg}$ NAA/liter and (B) E. zambesiaca on medium supplemented with 0.5 $\mathrm{mg} \mathrm{BA} /$ liter and $1.0 \mathrm{mg} \mathrm{NAA} / \mathrm{liter}$. Rooting after 12 weeks culture on hormone-free medium for $(\mathbf{C}) E$. comosa and (D) E. zambesiaca.

Hanks, G.R. and A.R. Rees. 1977. Growth regulator treatments to improve yield of twin-scaled $\mathrm{Nar}_{-}$ cissus. Scientia Hort. 6:237-240.

Hussey, G. 1975. Propagation of hyacinths by tissue culture. Scientia Hort. 3:21-28.

Hussey, G. 1977. In vitro propagation of some members of the Liliaceae, Iridaceae, and Amaryllidaceae. Acta Hort. 78:303-309. for rapid growth and bioassays with tobacco tissue cultures. Physiol. Plant. 15:473-479.

Nel, D.D. 1983. Rapid propagation of Lachenalia hybrids in vitro. South Africa J. Bot. 2(3):245-246.

Pierik, R.L.M. and B.J. Ippel. 1977. Plantlet formation from excised bulb scale segments of Nerine. Acta Hort. 78:197-202.
Murashige, T. and F. Skoog. 1962. A revised medium 